\title{
Championing cardiovascular health innovation in Europe
}

\author{
Michel Komajda ${ }^{1 * \ddagger}$, Andrew Coats ${ }^{2}$, Martin R. Cowie ${ }^{3}$, Neville Jackson ${ }^{4}$, Anders Svensson ${ }^{5}$, \\ Panagiotis Vardas'; The Cardiovascular Round Table (CRT) ${ }^{\dagger}$
}

\author{
${ }^{1}$ European Society of Cardiology, Sophia Antipolis, France \\ ${ }^{2}$ University of Warwick, Coventry, United Kingdom \\ ${ }^{3}$ Imperial College London, Royal Brompton Hospital, London, United Kingdom \\ ${ }^{4}$ Pfizer, New York, NY, United States of America \\ ${ }^{5}$ F. Hoffmann-La Roche, Basel, Switzerland
}

\section{Introduction}

The Cardiovascular Round Table (CRT) ${ }^{1}$ is an independent forum established by the European Society of Cardiology to facilitate the exchange of scientific knowledge between cardiologists and representatives of the pharmaceutical and medical device industries. Its purpose is to provide a noncommercial environment within which experts can freely discuss future issues in cardiovascular medicine and consider the merits of newdiagnostics and treatment techniques.

The CRT is concerned that a new epidemic of cardiovascular disease (CVD) is gaining ground in Europe as a result of the growing prevalence of metabolic disorders such as obesity and diabetes, and comes at a time when support for innovation in cardiovascular medicine is waning. The epidemic represents a massive challenge in terms of managing avoidable disease and death, but it is also a huge opportunity for EU universities, companies, and healthcare providers to be at the forefront of a global response.

A combination of innovation and prevention education campaigns is clearly needed. Investment to develop new treatments to combat the epidemic is, however, under threat from falling margins, particularly in the pharmaceutical sector. Increased regulation, high development costs, and slow time-to-market are all cited as reasons, and the consequence is a clear shift in R\&D focus to other geographical regions and medical areas likely to yield better returns.

This scenario will result in Europe's healthcare systems facing spiralling cost increases, while patients may not receive appropriate diagnosis and treatment. Europe could lose its leading position in cardiovascular-related research, science, and manufacturing just when emerging economies will have most need to pay for innovation.

Without decisive action, the CRT forecasts far-reaching social and economic consequences for Europe as the new epidemic takes hold. Already a major drain on national budgets, the outlook is likely to worsen considerably if left unchecked. Cardiovascular conditions currently account for over $10 \%$ of total healthcare expenditure across Europe and cause significant lost productivity through workplace absence. The social impact of disability, hospitalization, informal care arrangements, and premature deaths on family units cannot be measured but will inevitably have a major negative impact.

A sustained period of reduced investment could also precipitate a rapid decline in Europe's cardiovascular innovation and pharmaceutical industry, and lower its scientific and commercial influence. At risk is the major direct and indirect contribution ${ }^{2}$ to the European economy, export performance, and employment. Such a scenario would also damage Europe's ability to respond to the inevitable increase in global demand for new CVD treatments, drugs, and techniques. In making these predictions, the CRT does not seek to be alarmist. Its membership enjoys a unique perspective of the challenges to innovation from across the complete cardiovascular spectrum and lifecycle. The CRT's objective in writing this article is to raise the profile of patient needs and ensure that due consideration is given to closing the innovation gap.

While this article does not specifically address prevention education, the CRT firmly endorses the potential forawareness campaigns. These play a major role in influencing the lifestyle choices that lower risk exposure to CVD and metabolic conditions. The power of prevention strategies was well demonstrated by a study ${ }^{3}$ of the North Karelia region of Finland in which communications were integrated with primary healthcare alongside collaboration fromthe food industry. Over 25 years, male deaths from CVD reduced by $68 \%$.

\section{Background}

Every year, 4.3 million Europeans die $^{4}$ from the effects of CVD, while treatment and related costs are estimated at $€ 196$ billion/annum. It remains Europe's leading killer despite scientific advances that have arrested - and even reversed - the steep year-on-year mortality increase that used to characterize CVD statistics. ${ }^{5}$ By any measure, the global fight against CVD has been very successful. Re- 
the increase - or almost 4 full years - is due to reductions in CVD mortality alone. As positive as this scenario is, CVD remains by far the leading cause of death and the new epidemic has the potential to threaten the advances made to date. The same US research shows that increased life expectancy due to improved cancer therapies is only 3 months (Figure 1).

Many of the advances originated in Europe, the result of sustained R\&D innovation and cooperation between academics, cardiologists, scientists, and industry. Notable among them have been the following:

- diagnostic imaging tools including radiology and cardiovascular ultrasound;

- new interventional procedures for arrhythmias and coronary artery disease;

- development and exploitation of drug families including ACE inhibitors, statins, beta-blockers, ARBs, and antithrombotic/thrombolytic agents;

- better understanding of CVD risk factors.

Now, however, Europe is facing a series of emerging trends related to cardiovascular health that could threaten to overwhelm healthcare systems. The rapidly ageing European population is a factor that creates significant problems with many long-term implications. By 2050, the number of people over 50 will rise by $35 \%$ and over 85 by $300 \%$. Even if the current rates of diseases in these age groups remain static, many millions more Europeans will suffer from CVD.

There has been a dramatic rise in the detection of cardiometabolic disorders such as diabetes, while obesity is also a major concern. ${ }^{7}$ The International Diabetes Federation reports thatover 50 million adults in the EU have diabetes ${ }^{8}$ and that this number will grow to 64 million by 2030 . Other research suggests that $66 \%$ of these will die from heart disease or stroke. ${ }^{9}$ Recent work by the Chronic Diseases Collaborating Group ${ }^{10}$ asserts that, globally, one in nine adults has a measured body mass index $30 \mathrm{~kg} / \mathrm{m}^{2}$, while the International Association for the Study of Obesity (IASO) states that adult obesity rates in some EU27 countries exceeds $23 \%$. $^{11}$ The incidence of atherosclerosisrelated CVD is expected to accelerate and adverse lifestyle factors such as poor exercise regimes, high fat and sugar diets, and alcohol and tobacco consumption continue to present major risks, especially in the younger population.

Against this backdrop, it is not surprising that an increase in the number of European deaths from CVD and cardio-metabolic disorders is forecast. ${ }^{12}$ According to the WHO, CVD and diabetes accounted for over $50 \%$ of all global deaths from non-communicable diseases worldwide in 2008 and $30 \%$ of all deaths, while the global cost of treatment over the next 20 years has been estimated at a staggering $\$ 24$ trillion (Figure 2). ${ }^{12}$

To illustrate the scale of the epidemic faced by Europe,we can look at forecastsmade in the USA.The American Heart Association (AHA) warned in a recent Policy Statement that, by 2030 , over $40 \%$ of the US populationwill have at least one form ofCVD. ${ }^{13}$ This deeply concerning statistic has profound health and socio-economic implications for Europe, and clearly demonstrates a compelling need for R\&D to come up with new treatment strategies and products that support those strategies alongside, of course, prevention education.

Having noted the trends, and the difficulties in sustaining improved cardiovascular health levels, cardiologists have identified a number of key areas in which additional R\&D is urgently required:

- treatment of chronic and acute heart failure, especially when associated with preserved ejection fraction;

- prevention and treatment of cardio-metabolic diseases;

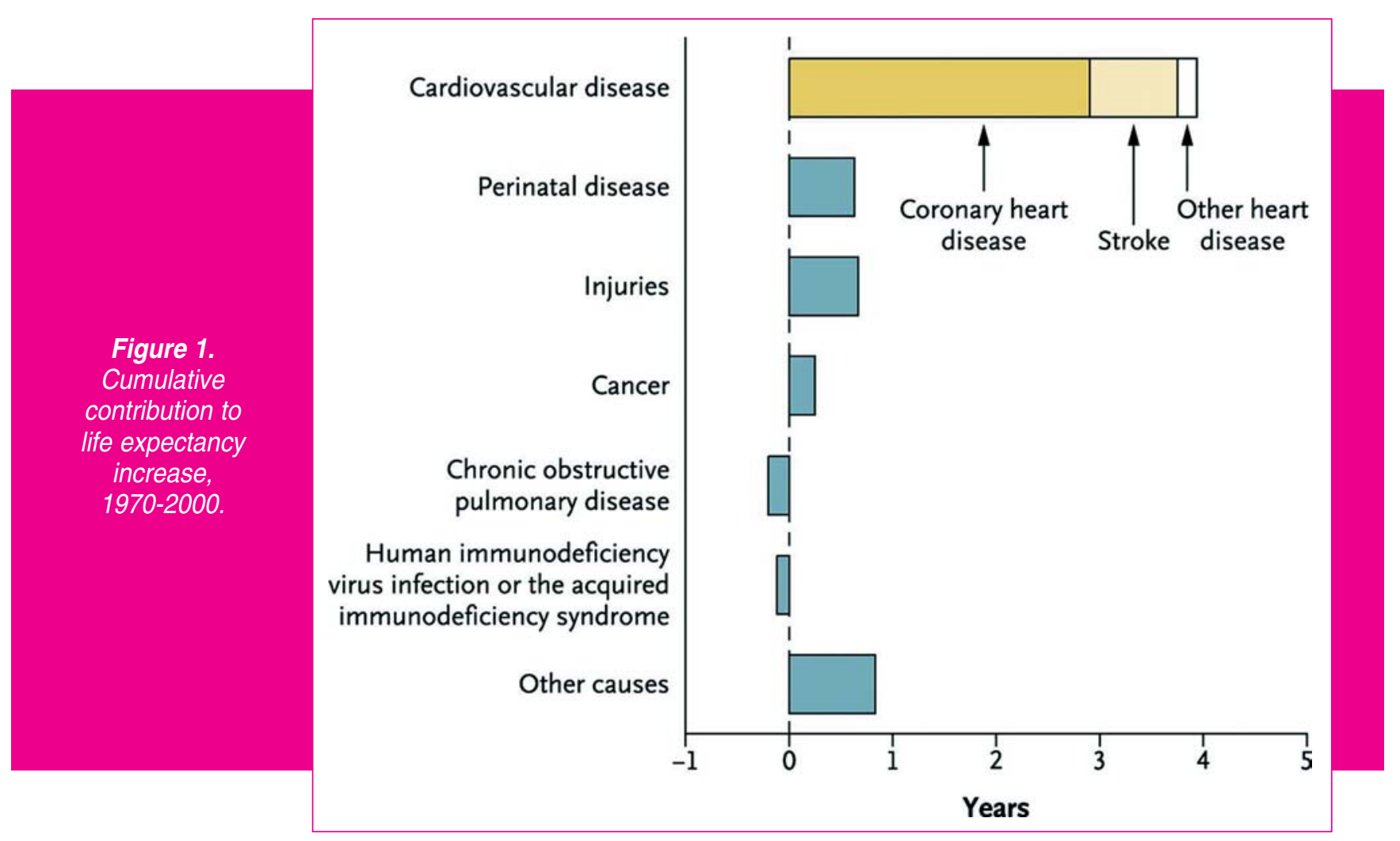




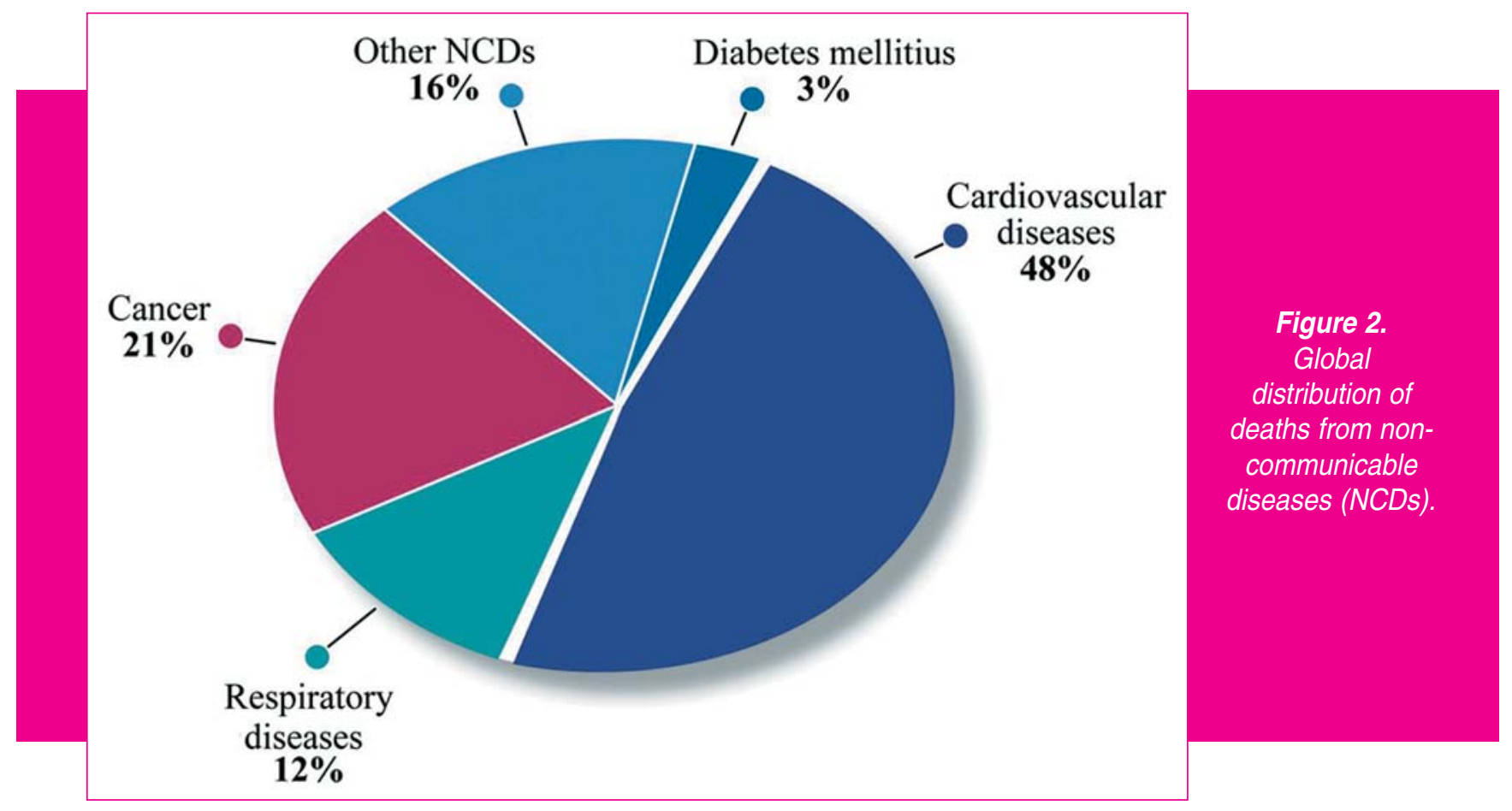

- treatment of arrhythmias, especially related to atrial fibrillation for which there is $25 \%$ prevalence in the $80+$ population;

- development of moreeffective and safer anti-thrombotic and antiatheroma drugs.

It is therefore worrying to observe that, when innovation is mostneeded, and indeed when the likelihood of future export opportunities is highest, R\&D activity in Europe appears to be stagnating. The CRT contends that European R\&D activity should be an absolute priority at least as long as cardiovascular disorders remain a leading cause of avoidable death.

\section{The innovation landscape}

Cardiovascular-related innovation in Europe is characterized by reductions in pharmaceutical $R \& D$ productivity and strong evidence that CVD is no longer regarded as a priority area. Research carried out byThomsonReuters suggests that global pharmaceutical $R \& D$ investment has failed to keep pace with sales growth and may have fallen since $2008 .{ }^{14}$ Over the period 2000-10, the analysis points to a $20 \%$ increase in time-to-market for new drugs with, almost certainly, a consequential increase in development costs. These findings clearly put pressure on those making investment decisions to ensure the best returns (Figure 3).

KMR Group, however, takes a different perspective and states that, while global pharmaceutical $R \& D$ activity is still rising, it is actually translating into fewer marketable products. 15 Its research indicates that the ratio of new molecular entities (NMEs) at pre-clinical development to those that eventually make it through to product approval has increased from 12:1 (2003Đ07) to 30:1 (2007-11). This trend is

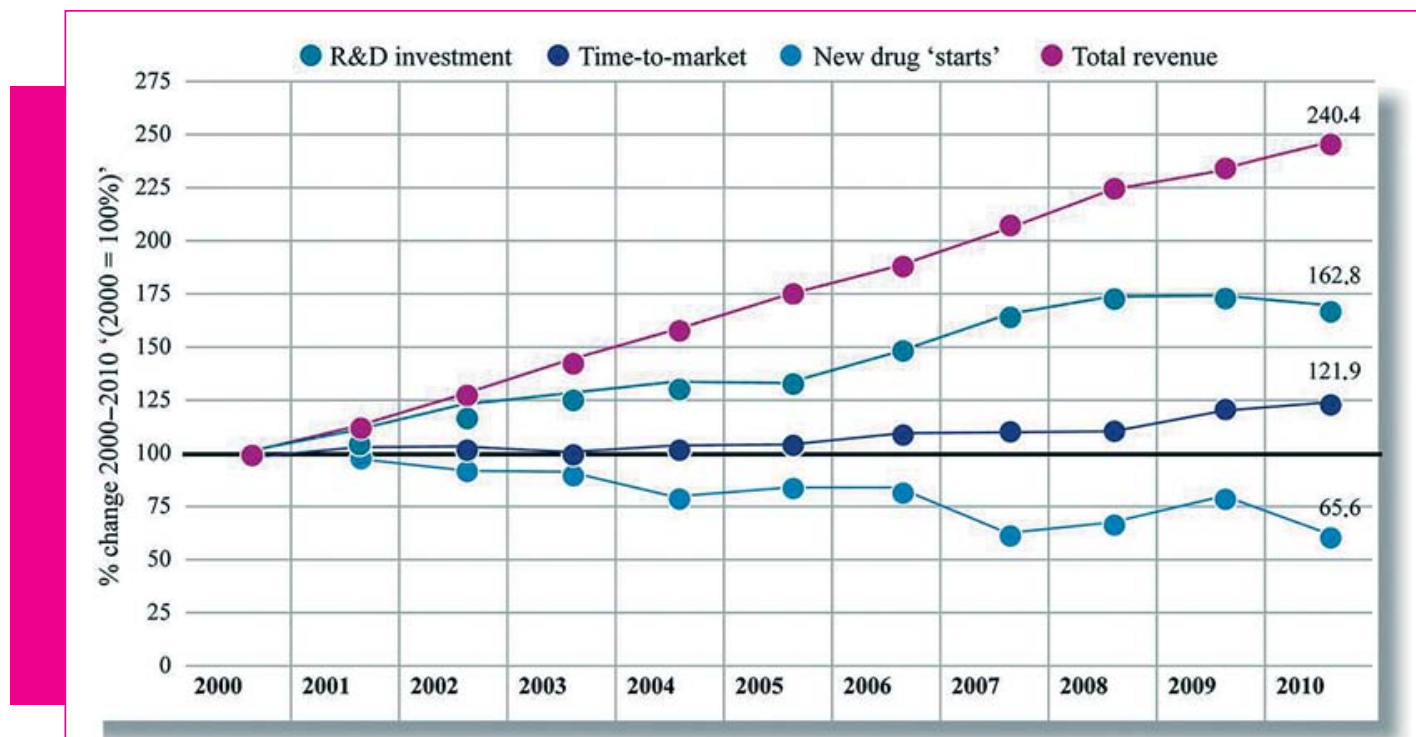

Figure 3.

Changes in

pharmaceutical industry productivity 2000-10. 
repeated at all stages of development and appears to show a 'kill' policy at the first sign of risk. In terms of cardiovascular innovation, both the WHO and the EU have recognized that R\&D activity is insufficient to meet the anticipated need. Yet, analysis by Thomson Reuters14 (see Figure 4) shows that the number of new CVD drug development programmes has dramatically reduced over the last few years and that CVD has not occupied a place in the Top 5 active research areas since 2005 .
CVD-related mortality remains the main cause of death, and cardiovascular morbidity is predicted to sharply increase.

\section{Europe's R\&D investment crisis}

The scale of the challenge facing Europe's pharmaceutical companies is shown in recent research ${ }^{19}$ by the European Federation of Pharmaceutical Industries Associations (EF-

\begin{tabular}{|c|c|c|c|c|}
\hline & & 2005 & 2007 & 2010 \\
\hline \multirow{6}{*}{$\begin{array}{l}\text { Figure } 4 . \\
\text { Active research } \\
\text { therapeutic } \\
\text { areas; } \\
2005-10 .\end{array}$} & Cancer & 217 & 313 & 312 \\
\hline & Infection & 76 & 106 & 113 \\
\hline & Neurological & 74 & 84 & 85 \\
\hline & Gastrointestinal & 55 & 78 & 66 \\
\hline & Endocrine & - & 75 & 57 \\
\hline & Cardiovascular & 53 & - & - \\
\hline
\end{tabular}

Other research has identified that cardiovascular-related $R \& D$ has experienced the biggest contraction in what is a general decline in overall R\&D activity. ${ }^{16}$ This is reinforced by US data that confirm that, of 2,900 drugs currently in $R \& D$, just 312 are targeted at CVD. ${ }^{17}$ Other US research shows the stark contrast between CVD drug development and CVD device development. ${ }^{18}$ In the area of valvular heart disease, for instance, there are just two drugs currently in trials, while the pipeline of new devices indicates a total of 20 in trials or awaiting approval (Figure 5).

The investment shift onto devices and other medical areas including cancer, infectious diseases, and neurology, although understandable, is nevertheless disturbing given that
PIA). This highlights that out of 5,000 R\&D 'starts', just one makes it to product launch while the Economist suggests that each new drug reaching market will cost an average of Euro 1.3 billion to develop. ${ }^{20}$ The decline in European cardiovascular R\&D productivity appears more marked than in other jurisdictions. This has been widely attributed to corporate pressure for higher returns on investment (ROI) from development projects in response to rapidly rising development costs driven by changes to European regulatory and clinical trial processes.

In a recent interview, Sir Andrew Witty, Chief Executive of GlaxoSmithKline, highlighted that the European market no longer drives investment decisions in the way it once did. ${ }^{21}$ He particularly cited pricing pressure and noted that year-

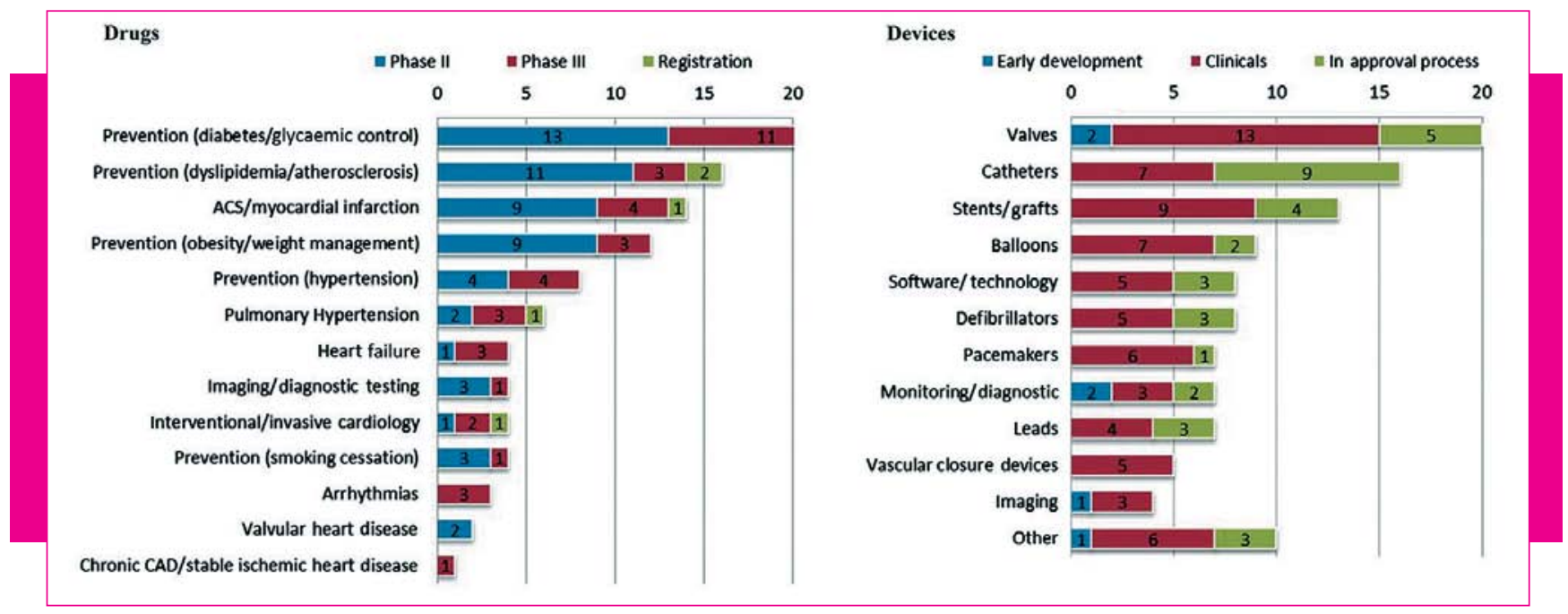

Figure 5. Pipeline comparison; cardiovascular drugs and devices. 
on-year reductions of 6-7\% were normal. He added, 'Europe is saying it's not very interested in new products. It doesn't mean we're not going to develop them for Europe but we're going to prioritize countries that want to prioritize innovation and that's clearly America, Japan and some of the leading countries in emerging markets.'

European R\&D is characterized by high costs due to lengthy timescales and a complex approval process, exacerbated by high wages and operational expenditure. ${ }^{22}$ This combination of rising cost and reducing revenues is clearly an unsustainable mix. Although Europe's 2001 Clinical Trials Directive established very high standards of patient safety, it has led to an environment that delays time-to-market and has deterred investment. Analysis shows a $15-25 \%$ decrease in the number of clinical trials conducted in Europe between 2007 and $2011 .^{23}$ Further evidence of the deteriorating situation is provided by research showing that the number of NME marketing approvals is stagnating. ${ }^{24}$

While reaffirming its total support for patient safety, the CRT welcomes the announcement that the Clinical Trials Directive is to be revised while noting that new procedures will not be ready until at least 2016 . It is vital to ensure that overzealous benefit and risk assessments do not delay this important initiative, and that it addresses major imbalances in the scale of patient trials under which oncology drugs can gain approval with far smaller and faster registration programmes than cardiovascular - yet another factor deterring CV-related investment.

Time-to-market is the crucial factor in making investment decisions. With a patent life of 20 years and a typical endto-end approval process in Europe that can exceed 15 years, there is only a short window to fully exploit intellectual property value. Reducing the process by just 1 year will have profound benefits to $R O I$ and to where $R \& D$ investment is committed. The recent closure of mainstream R\&D facilities in Europe by companies including Astra Zeneca, Merck, GlaxoSmithKline, Pfizer, and Sanofi is clear evidence of an investment crisis that has to be addressed and a regulatory environment that must be simplified.

Moving beyond the complexity of the regulatory environment, there are other factors which are contributing to the decline in CVD-related innovation in Europe. These include the following:

- Fragmentation on a number of fronts:

- each European country imposes unique pricing and reimbursement systems;

- research projects by government, academia, scientific bodies, and industry display multiple levels of responsibility;

- 'Open' markets encourage cross-border parallel trading.

- Austerity-led cost reduction programmes impact pricing, delay payment terms and increase the commercial risk of supply contracts.

- Costly post-approval regulatory demands affect pharmacovigilance and marketing processes.

\section{Innovation matters}

Innovation in Europe flourished because of regulated infrastructure, highly qualified and motivated scientific talent, open markets, and political stability. The European intellect has made significant contributions to techniques and treatments, with many notable achievements.

Innovation matters most, of course, to European patients. Improving the quality of life should, in itself, be the fundamental reason to resolve the innovation gap. However, innovation in cardiovascular R\&D also matters to taxpayers. The estimated financial burden of CVD is currently $€ 196$ billion annually of which $€ 105$ billion is direct healthcare costs, with a further $€ 47$ billion assessed as the loss of productivity across the European economy due to sickness and absence and $€ 44$ billion as the costs of informal family-based care.

In addition, pharmaceuticals is a strategic industry across Europe. Its economic importance is demonstrated by 2010 estimates ${ }^{1}$, which show a trade balance of $€ 70$ billion on total exports worth $€ 270$ billion, and total employment of 640,000 . R\&D alone employs 115,000 highly qualified staff, and has an annual budget of $€ 27$ billion. This represents $17 \%$ of Europe's total business R\&D investment across all industrial sectors.

The lack of CVD innovation inevitably has consequences. Shifting the focus of R\&D from cardiovascular to other medical areas may well satisfy short-term business imperatives but does nothing to improve CVD morbidity and mortality. Shifting the focus of R\&D away from Europe will have a major impact on economic performance, social cohesion, and scientific knowledge.

Despite current concerns, Europe still offers positive advantages as a location for cardiovascular-related R\&D:

- established EU-wide processes for quality control and regulatory approval;

- extensive, mobile talent pool including experienced researchers;

- proximity to leading universities with a track record in innovation and fundamental research;

- track record of collaboration between industry and academia;

- access to important data sources;

- EU funding and support for innovation;

- established government research organizations;

- pan-European cooperation.

\section{Recommendations}

Stakeholders should urgently come together in a forum to openly discuss the issues raised in this article and allocate actions. As a minimum, the participants should be drawn from the EU, national healthcare authorities, national finance ministries, academia, medical societies, and representatives of the pharmaceutical and medical device industries. The agenda needs to focus on the following:

- to undertake a review of the issues that are driving R\&D investment to other jurisdictions;

- to develop and implement a strategic plan that reverses the decline in cardiovascular-related R\&D in Europe;

- to simplify the clinical trials environment for new CV drugs and devices;

- to better target EU funding and investment through, for instance, tax incentives and sponsored development programmes; 
- to encourage Europe's pharmaceutical industry to develop the necessary drugs;

- to consolidate and extend Europe's proven scientific leadership and successful track record;

- to review patent duration in the context of development timescales and scale of investment;

- to encourage cross-border and cross-discipline collaboration and networking;

- to improve communications between professional cardiovascular and cardio-metabolic communities and the pharmaceutical industry on one side, and patients on the other.

\section{Call to action}

\section{The CRT invites:}

- EU institutions and national governments to commit to steps that establish a more favourable environment for cardiovascular R\&D however it is funded.

\section{Received: $9^{\text {th }}$ Aug 2013}

*Address for correspondence: European Society of Cardiology, Heart House, 2035 Routes Des Colles, 06903 Sophia Antipolis, France.

Phone: +33492947600

Fax: +33142163020

Email: michel.komajda@psl.aphp.fr; escboard@escardio.org
- EU institutions and national governments to allocate additional public funding to encourage more cardiovascular R\&D programmes and respond to the threat to public health.

- policy makers to measure and analyse the cost of inaction compared with the benefits of a vibrant cardiovascular $R \& D$ environment.

- policy makers to investigate and propose forward-looking regulatory measures that balance patient safety with a climate for genuine R\&D innovation.

- pharmaceutical companies to review the commercial risk environment relating to cardiovascular $R \& D$ and reassess investment decisions in light of the potential epidemic.

- cardiologists and scientists to make concerted efforts to identify further needs in CVD, prioritize them, highlight them, and lobby for pre-emptive funding to address the expected increase in NCDs.

These actions, together with aggressive promotion of prevention strategies including lifestyle factor changes, can address the threat of a cardio-metabolic epidemic in Europe.

Conflict of interest: The views expressed in this article represent a consensus of the authors and do not necessarily reflect the views of the organizations that employ, retain, or contract with the authors.

\section{Literature}

1. Cardiovascular Round Table. An Introduction to the CRT http://www.esc-crt.org/about/Pages/about.aspx.

2. EFPIA. The Pharmaceutical Industry in Figures. 2011. Update http://www.efpia.eu/sites/www.efpia.eu/files/EFPIA_Figures_2012_Final-20120622-003-EN-v1.pdf.

3. Puska P, Nissinen A, Tuomilehto J, et al. The community-based strategy to prevent coronary heart disease: conclusions from the ten years of the North Karelia Project. Annu Rev Public Health. 1985;6:147-93.

4. Nichols M, Townsend N, Luengo-Fernandez R, Leal J, Scarborough P, Rayner M. Brussels; European Cardiovascular Disease Statistics 2012 European Heart Network European Society of Cardiology, Sophia Antipolis.

5. Sipido K. Identifying needs and opportunities for advancing translational research in cardiovascular disease. Cardiovasc Res. 2009;83:425-35.

6. Lenfant C. Clinical research to clinical practice-lost in translation? N Engl J Med. 2003;349:868-74

7. European Commission White Paper on A Strategy for Europe on Nutrition. Overweight and obesity related health issues http://ec.europa.eu/health/archive/ph_determinants/life_ style/nutrition/documents/nutrition_wp_en.pdf.

8. Federation of European Nurses in Diabetes and International Diabetes Federation. The policy puzzle. Is Europe making progress? Http://ec.europa.eu/health/major_chronic_diseases/docs/policy_puzzle_2011.pdf.

9. Roger VL, Go AS, Lloyd-Jones DM. Heart disease and stroke statistics-2011 update: a report from the American Heart Association. Circulation. 2011;123:e18-e209.

10. Anand S, Yusuf S. Stemming the global tsunami of cardiovascular disease. Lancet. 2011;377:529-32.

11. International Association for the Study of Obesity. Overweight and obesity in the EU27 http://www.iaso.org/site_media/uploads/v2PDFforwebsiteEU27.pdf.

12. World Economic Forum and the Harvard School of Public Health. 2011. The global economic burden of non-communicable diseases September http://www3.weforum.org/docs/ WEF_Harvard_HE_GlobalEconomicBurdenNonCommunicableDiseases_2011.pdf.

13. Heidenreich PA. Forecasting the future of cardiovascular disease in the United States: a policy statement from the American Heart Association. Circulation. 2011;123:933-44.

14. Thomson Reuters. The changing role of chemistry in drug discovery http://thomsonreuters.com/content/science/pdf/ls/iyc2011.pdf.

15. SCRIP Intelligence report. Kill, kill, kill! The worrying mortality of pharma pipelines http://www.scripintelligence.com/home/Kill-kill-kill-The-worrying-mortality-of-pharma-pipelines335166.

16. Pammolli F, Magazzini L, Riccaboni M. The productivity crisis in pharmaceutical R and D. Nat Revi Drug Discov. 2011;10:428-38.

17. US Pharmaceutical Industry Report, 2008-2009 http://www.pr-inside.com/us-pharmaceutical-industry-report-r1291427.htm.

18. Laslett LJ. The worldwide environment of cardiovascular disease: prevalence, diagnosis, therapy, and policy issues. J Am Coll Cardiol. 2012;60:S1-S49.

19. EFPIA. Lifecycle of a new medicine http://www.efpia.eu/Content/Default.asp?PagelD=361EFPIA.

20. The Economist. 2011. The future of healthcare in Europe. Economist Intelligence Unit Report See table page 42.

21. The Telegraph. 2013. Witty lays out Glaxo vision with UK in lead Feb http://www.telegraph.co.uk/finance/newsbysector/pharmaceuticalsandchemicals/9859739/Witty-lays-outGlaxo-vision-with-UK-in-lead.html.

22. Mroczkowski T. The New Players in Life Science Innovation. 1st ed. New Jersey: FT Press; 2011. p. 25.

23. Mroczkowski T. The New Players in Life Science Innovation. 1st ed. New Jersey: FT Press; 2011. p. 165.

24. European Medicines Agency. 2011. Monthly Statistics Report September http://www.ema.europa.eu/docs/en_GB/document_library/Report/2011/10/WC500116972.pdf. 